\title{
Adolescent Hookah Pipe Use: Exploring the Role of Basic Psychological Needs and Motivation
}

\author{
Zainab Kader' (iD, Rik Crutzen², \\ and Nicolette Vanessa Roman'
}

\begin{abstract}
Background: Adolescent hookah pipe use is on the rise despite it being a public health concern. Several studies focus on the external determinants of adolescent hookah pipe use but research focusing on the internal factors motivating adolescents to smoke the hookah pipe is sparse. Objective: Drawing on self-determination theory, a contemporary theory of human motivation, this study aimed to explore the basic psychological needs (BPN) and motivation of adolescent hookah pipe users and nonusers in an attempt to explore whether satisfaction or frustration of needs contributes to hookah pipe use. Method: Thirty adolescents, aged 13 to 19 years, participated in the qualitative study using one-on-one semistructured interviews. Each interview was audio recorded, transcribed, and thematically analysed. Results: This study revealed that satisfaction or frustration of BPN, particularly competence and relatedness influences adolescents' decision to smoke or not smoke the hookah pipe. Hookah pipe users experience more needs frustration compared to hookah pipe nonusers.
\end{abstract}

\footnotetext{
'University of the Western Cape, The Centre for Interdisciplinary Studies of Children, Families and Society, Cape Town, South Africa

2Maastricht University/CAPHRI (Care and Public Health Research Institute), Maastricht, Netherlands
}

\section{Corresponding Author:}

Zainab Kader, The Centre for Interdisciplinary Studies of Children, Families and Society, Faculty of Community and Health Sciences, University of the Western Cape, Robert Subukwe Road, Bellville, Cape Town 7925, South Africa.

Email: zkader4@gmail.com 
Furthermore, hookah pipe users are more extrinsically motivated to smoke, whereas hookah pipe nonusers are intrinsically motivated not to smoke. Conclusion: The internal factors associated with adolescent hookah pipe use is a relatively new perspective.

\section{Keywords}

hookah pipe, health risk, adolescents, self-determination theory, basic psychological needs, motivation

\section{Introduction}

Hookah pipe use has become a major public health concern over the past two decades (Kader et al., 2019). The hookah pipe is a vessel used to smoke flavored tobacco (Moreno, 2015). The emerging trend of hookah pipe use has become increasingly popular over the past few years, among adolescents (Marshall et al., 2016; Petersen, 2018), with the global prevalence rates varying from $6 \%$ to $34 \%$ in the Middle East to $5 \%$ to $17 \%$ in the United States and $39.6 \%$ in the United Kingdom (Maziak et al., 2015; Jawad \& Power, 2016; World Health Organization, 2015). A study in a poor urban community in Johannesburg, South Africa, found that $20 \%$ of high school students reported daily use, and $60 \%$ of the population reported having used it (Combrink et al., 2010).

Adolescents view hookah pipe smoking as a social behaviour that is fun, relaxing, socially acceptable, and harmless (Eshah \& Froelicher, 2017). However, the hookah pipe contains condensed carbon monoxide, tar, nicotine, and other heavy materials that may pose health risks such as cancers, respiratory and cardiac problems, mouth ulcers, and periodontal diseases (Bashirian et al., 2019). The health hazards of hookah pipe smoking are even higher than other forms of tobacco consumption because of the method of smoking (sharing mouthpieces, exposure to carbon monoxide, and longer periods of smoking; Daniels, 2012). Due to the smoking methods, the hookah pipe is also a potential carrier and viral transmitter of COVID-19 because not only is the mouthpiece shared but multiple users touch the hookah pipe, which could potentially be infected, and people sit in close proximity to each other, which makes it easier for respiratory droplets to be transferred.

The rise of hookah pipe use can be partly attributed to the lack of recreational activities in communities, peer pressure, addiction, a sense of relaxation, and the perception that hookah pipe smoking is less harmful than 
cigarette smoking (Combrink et al., 2010; Daniels, 2012; Peer, 2018). There is less insight, however, into the role of motivation guiding this behaviour. Exploring the health risks of hookah pipe use from a psychological perspective is valuable because it allows for an understanding of why adolescents smoke the hookah pipe. When an understanding is developed, it forms a basis for intervention (Bartholomew et al., 2016). According to self-determination theory (SDT; Deci \& Ryan, 2000), there is a motivational continuum ranging from being intrinsically motivated (engaging in activities because of the inherent interest and enjoyment of the activity) to extrinsically motivated (influenced by external rewards and punishments) and, ultimately, being amotivated (Ryan et al., 2006). Satisfaction and frustration of basic psychological needs (BPN) results in an individual being more or less intrinsically motivated. The three BPN proposed by SDT are (1) autonomy-behaving with a sense of volition, (2) competence - a sense of mastery, and (3) relatedness - a sense of feeling connected to others (Deci \& Ryan, 2000). These might also be relevant for hookah pipe use. For example, when adolescents are autonomous and they take a stand about their choice to smoke the hookah, they are less likely to be influenced by others (Ramji et al., 2019). However, when adolescents do not receive adequate support, they may lack the motivation to stop (Ramji et al., 2019). In general, when these psychological needs are frustrated, negative psychological consequences such as maladjustment, aggression, or low confidence may occur (Kuzucu \& Şimşek, 2013). People are also often motivated to pursue maladaptive behaviors, such as smoking, in efforts to satisfy their needs (Li et al., 2019).

In an attempt to understand hookah pipe use from a humanistic perspective, it is important to gain more insight into the contributory role of motivation and BPN, which is the focus of this study. Adolescents residing in the Western Cape, South Africa participated in a qualitative study using one-onone semistructured interviews. Interviews were conducted at the participants' school. This study formed part of a larger project which aimed to design an intervention to reduce adolescent hookah pipe use and satisfy BPN.

\section{Method}

\section{Participants}

A total of 30 participants participated in this study of which 14 were hookah pipe users and 16 were hookah pipe nonusers. Participants' ages ranged from 13 to19 years old $(M=16)$ and their school grade ranged from 7 to $12(M=$ 10). The majority of the participants were male, English speaking, and of 
mixed race. From the 12 schools that participated in the larger project, four schools were selected to participate in this study. The schools were selected based on setting (rural and urban), school fees (nonfee paying and fee paying), socioeconomic status of the community (low and middle), and ability to accommodate the researcher during the data collection period. To have a heterogeneous sample, users and nonusers who were representative in terms of area, race, age, and gender were identified based on data from a previous quantitative study.

\section{Study Design}

Adolescents residing in the Western Cape, South Africa participated in a qualitative study using one-on-one semistructured interviews. Interviews were conducted at the participants' school. This study formed part of a larger project which aimed to design an intervention to reduce adolescent hookah pipe use and satisfy BPN. All reporting in this study is in accordance with the COREQ (Consolidated criteria for Reporting Qualitative research) checklist (Tong et al., 2007). The data has been deposited in OSF (https://osf.io/m472p/ quickfiles).

\section{Data Collection}

To ensure that the interview schedule was applicable and that the questions were understandable to the participants, two pilot interviews were conducted with Grade 7 learners aged 12 years old. These adolescents were not included in the main study.

A brief questionnaire was used to determine participants' demographics. The development of the interview schedule was guided by SDT and the results of the quantitative study that was part of the project. Interviews were conducted in the participants' language of choice, either English or Afrikaans, and lasted between 45 and 60 minutes. Data collection continued until saturation occurred. All interviews were audio recorded and field notes were taken during the interviews. Data was transcribed verbatim. Afrikaans transcriptions were then translated into English by a person proficient in both languages. Accuracy of translations was confirmed by a native Afrikaans speaker who is proficient in both languages. The researchers and participants knew that the transcripts would not be returned to the participants as it would not be possible to access the participants again due to resource constraints. Therefore, thorough clarification of views and experiences occurred during the interview to ensure accuracy. 


\section{Data Analysis}

SDT was used as a framework for data analysis. Data and field notes were analysed by two researchers. The analysis followed the six phases of thematic analysis outlined by Braun and Clarke (2006). The six phases included

1. Familiarizing oneself with the data by carefully reading the transcripts in an attempt to make meaning.

2. Generating initial codes based on what is considered interesting and meaningful based on the objectives of the study.

3. Searching for themes by collating relevant coded data extracts together and forming potential themes.

4. Reviewing themes by refining the potential themes either by collapsing, merging, accepting, or discarding the potential themes.

5. Defining concepts by identifying the essence of what each theme is about.

6. Reporting the findings in the form of a manuscript. ZK and NVR were involved in the analysis process. Any discrepancies were discussed with RC. Final codes and themes were generated from the data after consensus was reached between the three researchers.

\section{Ethical Considerations}

Permission to conduct the study was provided by the Western Cape Education Department and the Human Social Sciences Research Ethics Committee at the University of the Western Cape. The study's aim, objectives, and processes were explained to the participants and their parents in a way that they could understand by means of an information letter. Participation was voluntary and withdrawal was permitted at any time. Participant written assent (for participants younger than 18 years), their parents' consent, as well as consent for participants older than 18 were provided. Participants were informed that the interviews would be audio recorded. Each audio-recording and transcript received a number so that no names were used in the process. In cases where the questions evoked emotions that needed containment, a registered counsellor was available to offer support, containment, crisis intervention, or an appropriate referral.

\section{Trustworthiness}

Trustworthiness was achieved by ensuring that the study was credible, dependable, confirmable, and transferable. To ensure credibility, two 
researchers were involved in coding, analyzing, and interpreting data in order to make decisions. For the findings to be dependable and confirmable, all research steps were transparent and copious records of the research process was kept throughout the study. Transferability was achieved by including thick quotations of participants (Korstjens \& Moser, 2018; Lincoln \& Guba, 1985).

\section{Reflexivity}

Introspective reflexivity was used in this study as it allowed the researchers to recognise the attitudes, experiences, and emotions that could have affected engagement with the participants and the data analysis. Researchers also bracketed their biases and attitudes before analyzing the data (Sorsa et al., 2015). This involved (1) preaction bracketing - where attitudes, emotions, and ideas that were likely to influence the data were identified and dealt with; (2) in-action bracketing during the empirical work; and (3) bracketing on action - use of new insights in subsequent empirical work.

\section{Results}

Table 1 compares adolescents' views of their BPN and motivation by presenting adolescent's quotes. Six themes were generated: (1) autonomy, (2) competence, (3) relatedness, (4) intrinsic motivation, (5) extrinsic motivation, and (6) amotivation. Subthemes were generated from the main themes (Table 1). Table 2 provides a snapshot of the adolescents' views of their BPN and motivation.

\section{Basic Psychological Needs}

Autonomy. The majority of hookah pipe users relied on their parents to assist with decision making, while the majority of nonusers relied on parents, grandparents, or prayer to help with decision making. Users felt that their parents wanted to control their lives and there was a sense of dependence. Users appeared more cautious or insecure about making decisions. For example, a 15-year-old male user indicated, "I can't do anything without my mother's permission. I need to let her know before I do it" and a 15-year-old male nonuser stated, "my grandpa helps with decisions. He is strong and has overcome a lot. He is my role model. I always go to him for guidance."

Hookah pipe users and nonusers who made their own decisions indicated that they were not comfortable asking parents for assistance. This was evidenced by a 15 -year old female user stating, "I make decisions all by myself 


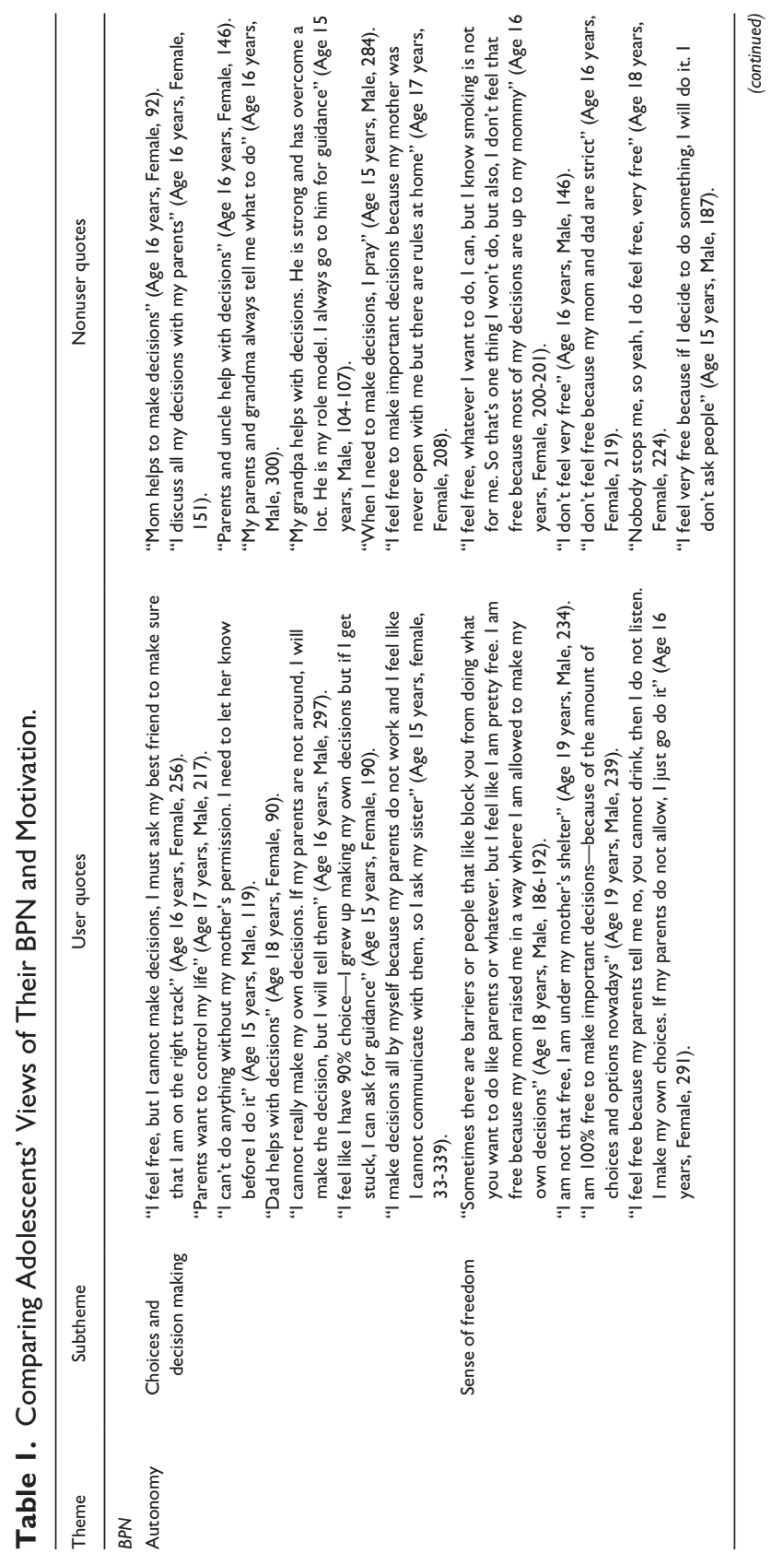




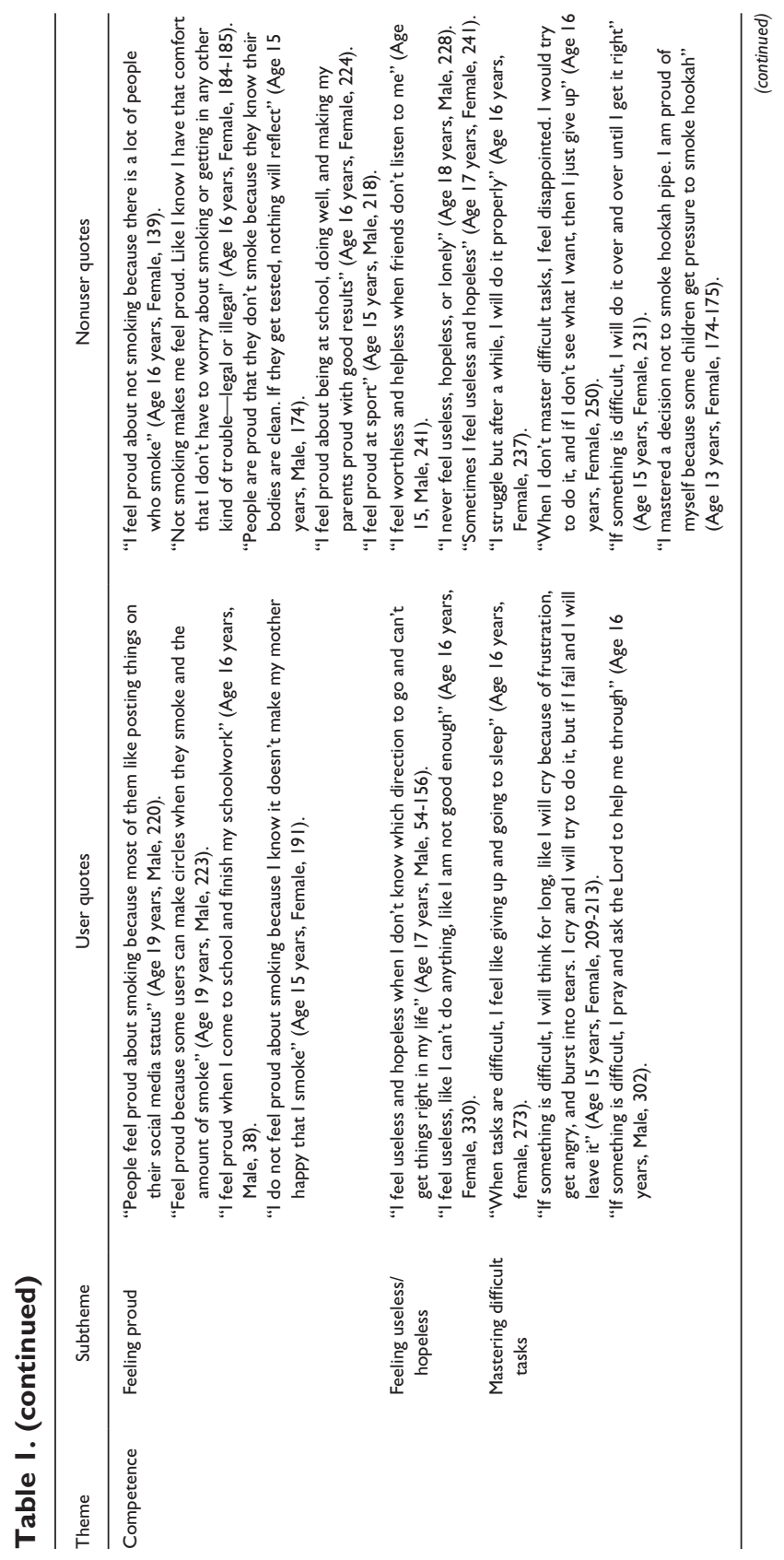




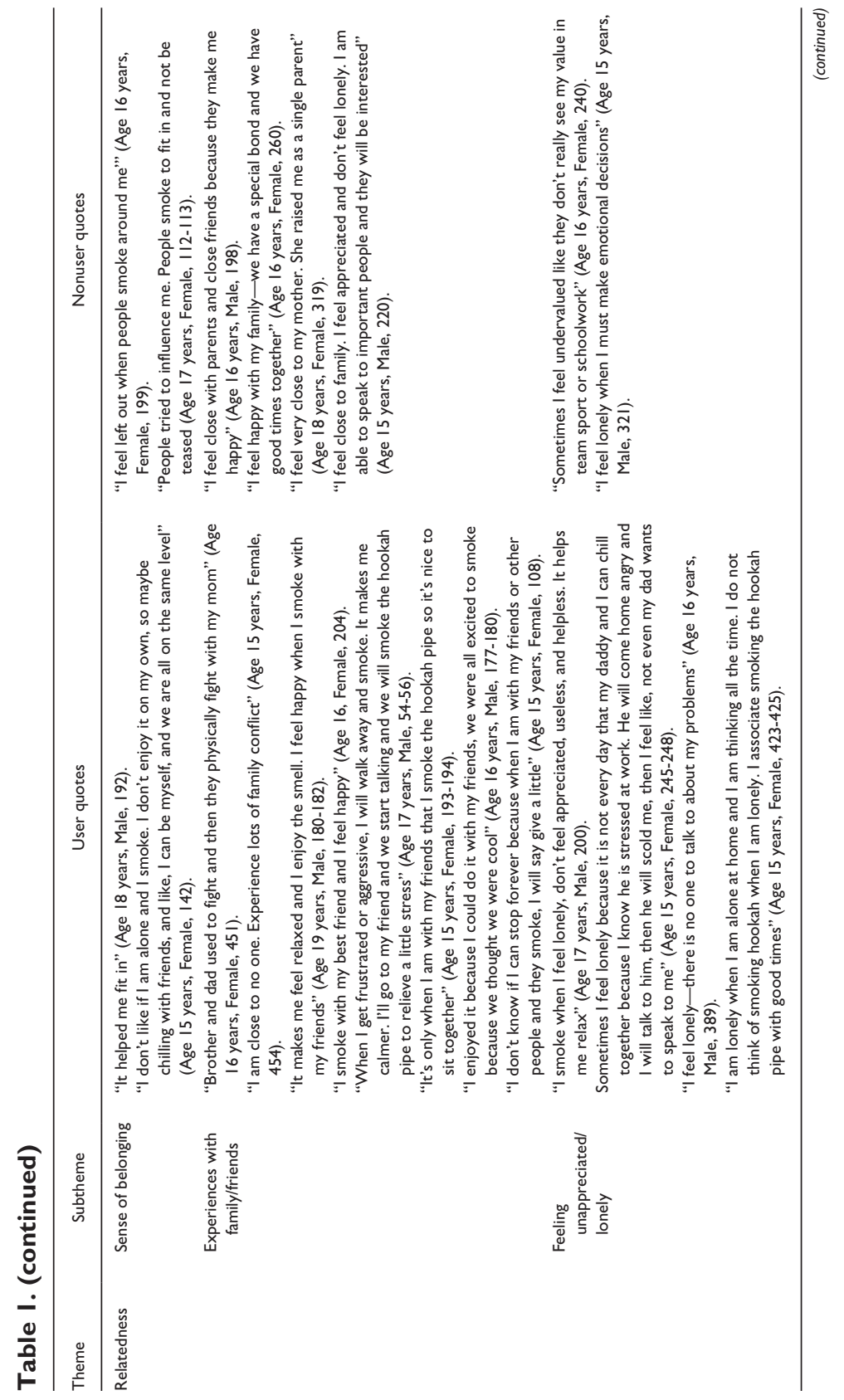




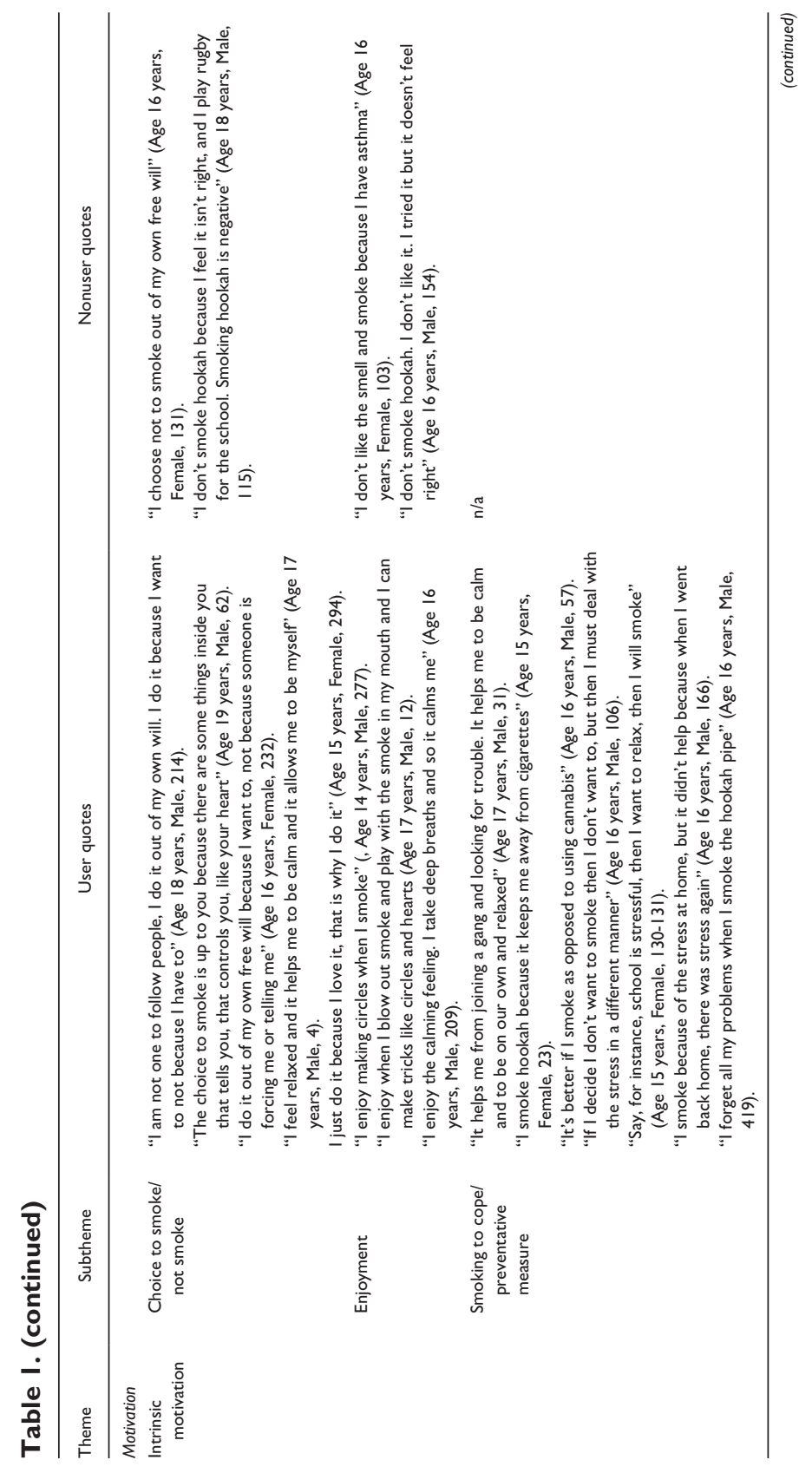




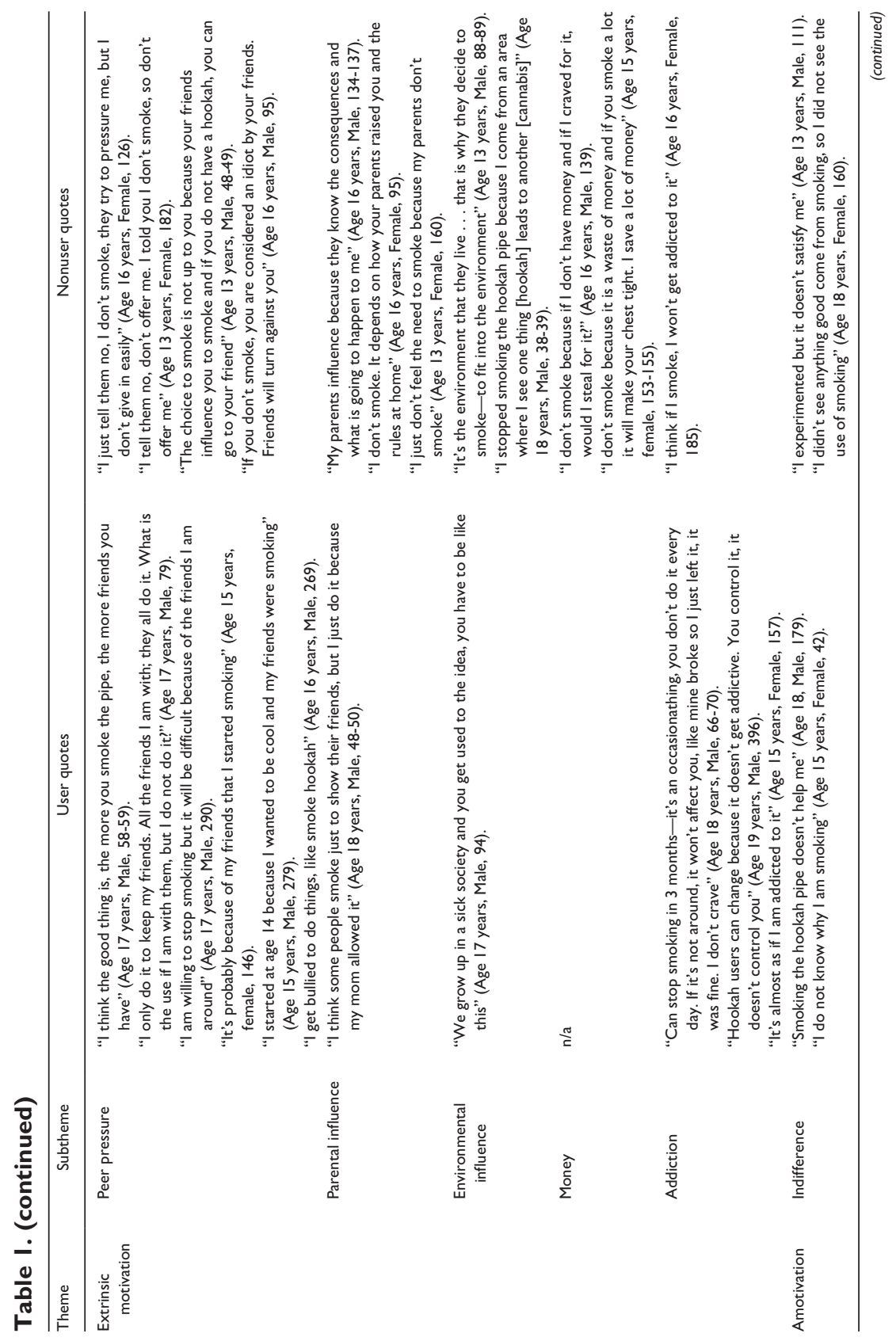




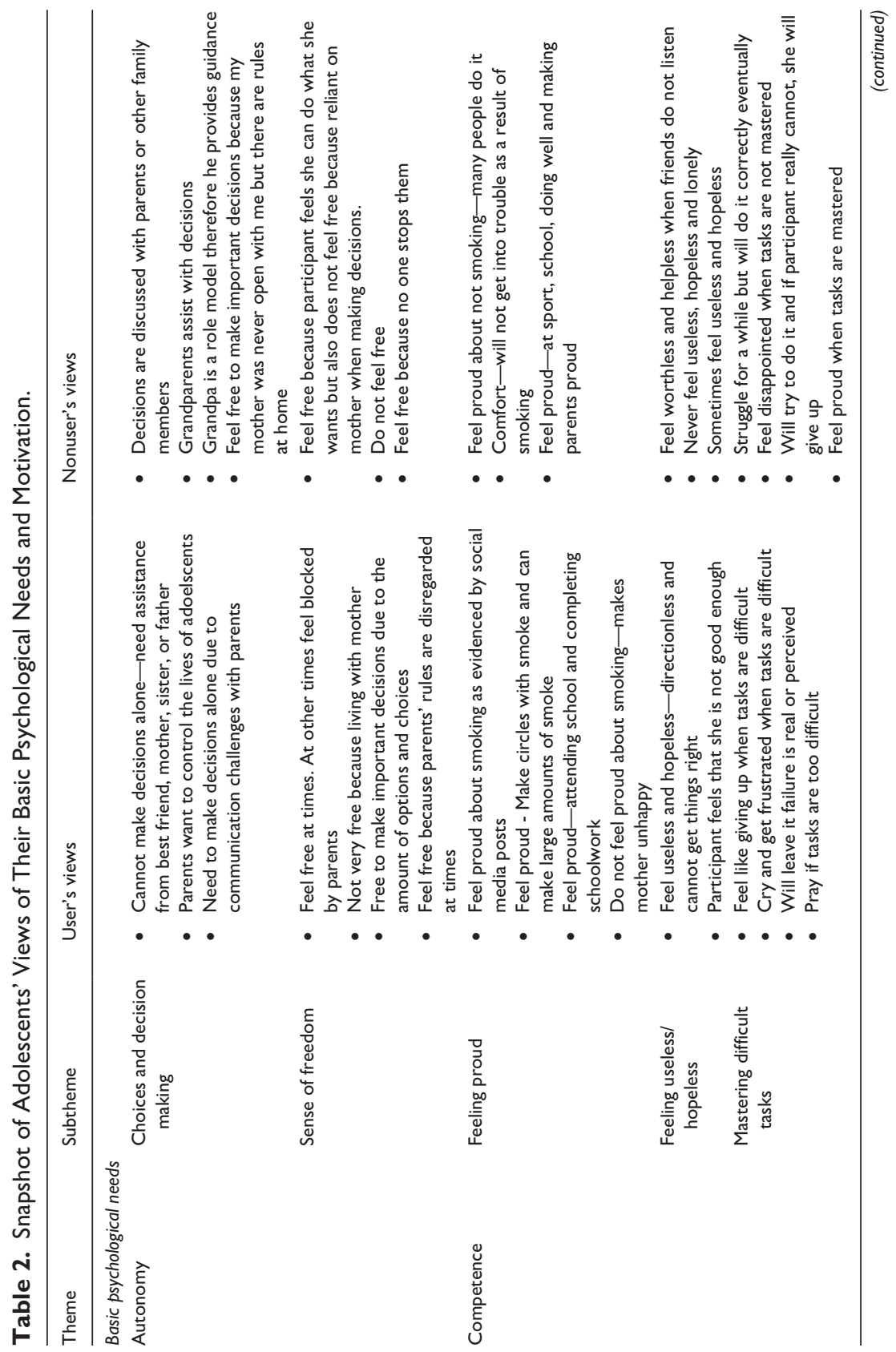




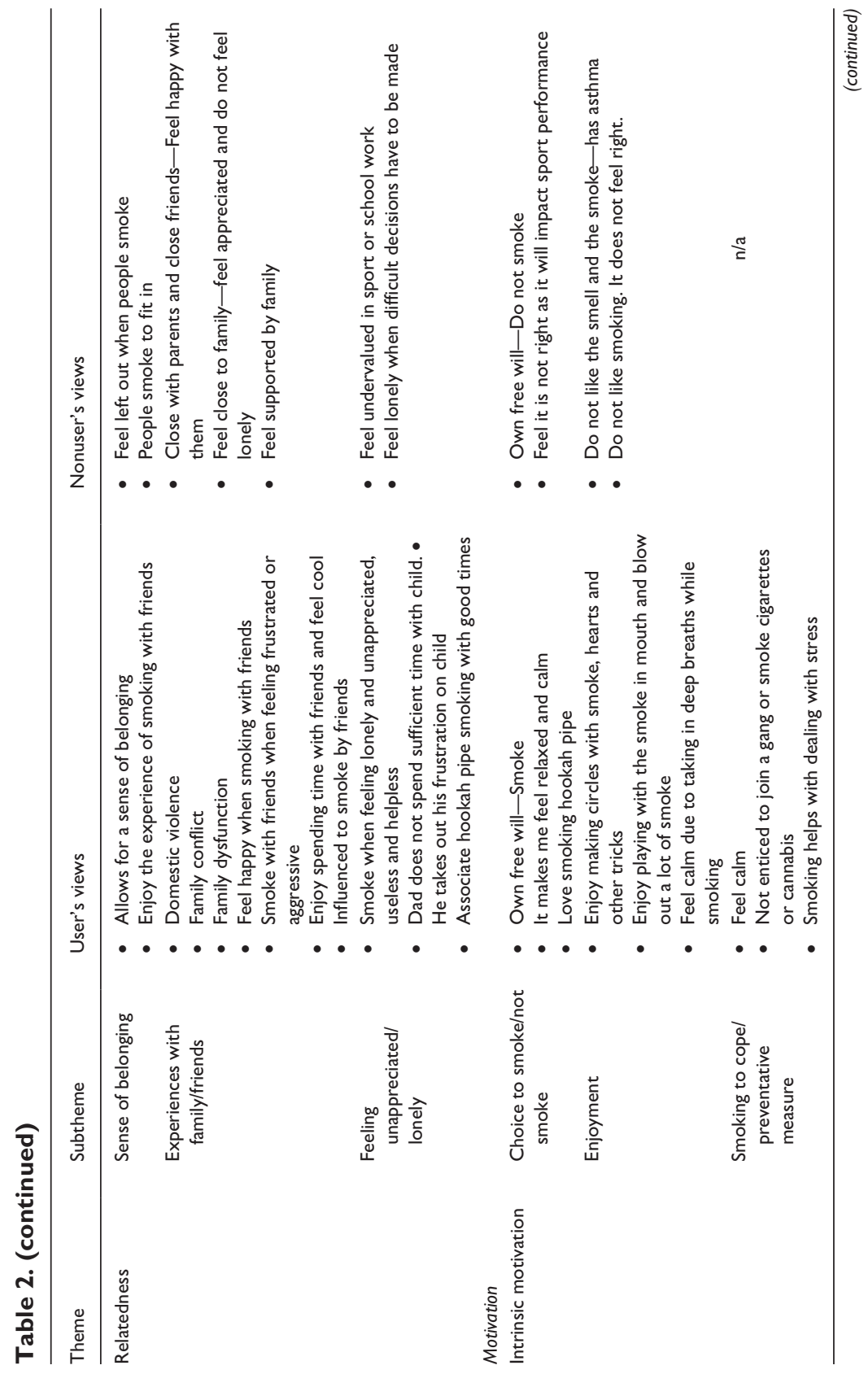




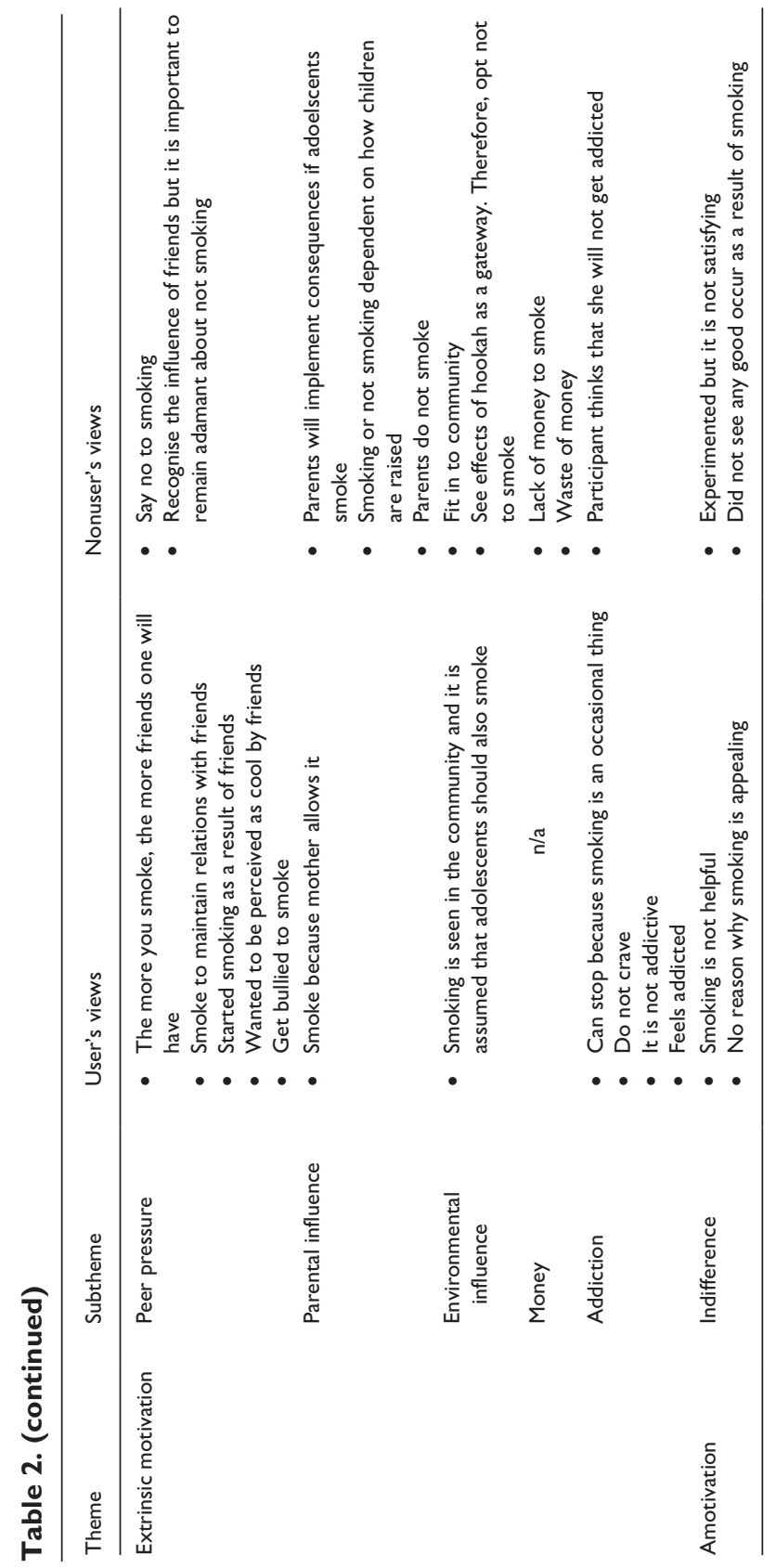


because my parents do not work and I feel like I cannot communicate with them, so I ask my sister" and a 17-year-old female nonuser stating, "I feel free to make important decisions because my mother was never open with me but there are rules at home."

Even though users clearly reported that they struggled to make decisions independently, they reported feeling free and able to make choices. This was emphasized by a 16-year-old female user who stated, "I feel free because my parents tell me no, you cannot drink, then I do not listen. I make my own choices. If my parents do not allow, I just go do it."

When the contradiction was raised about feelings of autonomy, users said they can make day-to-day choices, but they needed support for important decisions. Important decisions differed from person to person, such as remaining in school, attending parties, drinking alcohol, and living arrangements, to name a few. Users made reference to making choices as a form of rebellion and felt that they would do something whether their parents approved.

Some hookah pipe users and nonusers felt that they were not free because they lived with their parents as evidenced by a 19-year-old male user who stated, "I am not that free, I am under my mother's shelter" and a 16-year-old nonuser who indicated, "I don't feel free because my mom and dad are strict"

In sum, there is no definitive indication that adolescents' sense of autonomy affects their choice to smoke the hookah pipe or not because of the similarities in their responses.

Competence. Some hookah pipe users felt proud about smoking because they were able to do tricks with the smoke, such as making shapes with the smoke, or producing a large amount of smoke. There was the perception that when one posts on social media about smoking the hookah pipe, one is boasting about smoking, so there was a sense of pride associated with the practice. A 19-year-old male user highlighted, "people feel proud about smoking because most of them like posting things on their social media status."

However, one 15-year-old hookah pipe user did not feel proud about smoking because she knew that it did not make her mother happy. She reflected and stated, "I do not feel proud about smoking because I know it doesn't make my mother happy that I smoke."

Hookah pipe nonusers, on the other hand, were proud that they did not smoke. The pride was associated with not conforming to social trends. Both hookah pipe users and nonusers felt proud about performing well at school as they shared, "I feel proud about being at school, doing well, and making my parents proud with good results." 
Even though hookah pipe users expressed pride in smoking, they reported a greater sense of feeling useless and hopeless in life when they were unsure about which direction to follow, and they struggled to manage when things did not go according to plan. A 16-year-old female user shared, "I feel useless, like I can't do anything, like I am not good enough."

Some nonusers also reported feeling useless and helpless, but their experiences were influenced by friends, whereas users' feelings appeared more internalized where they felt that they were not good enough. Some nonusers reported feeling useless or helpless on occasion, while others did not experience this at all. For example, a 15-year-old male nonuser shared, "I feel worthless and helpless when friends don't listen to me."

When trying to master difficult tasks, hookah pipe users were more likely to give up as a result of frustration or anger. Hookah pipe nonusers, on the other hand, were more likely to persevere or struggle until they completed the task. On the whole, users appear to experience more needs frustration with regard to competence compared with nonusers. Hence, their reliance on the hookah pipe for needs satisfaction.

Relatedness. Hookah pipe users and nonusers reflected on their sense of relatedness in terms of their sense of belonging, their experience with family and friends, and their experience of feeling unappreciated or lonely. A 15-yearold female user reported, "I don't like if I am alone and I smoke. I don't enjoy it on my own, so maybe chilling with friends, and like, I can be myself, and we are all on the same level." Smoking the hookah pipe in a peer group rather than alone provided users with enjoyment and a sense of belonging.

While some nonusers felt left out when people smoked around them, they opted not to smoke despite peer pressure as emphasized by a 16-year-old female nonuser who stated, "I feel left out when people smoke around me." Instead, they described positive experiences with their parents and close friends. For example, a 16-year-old female nonuser articulated, "I feel happy with my family - we have a special bond and we have good times together."

In contrast, the majority of users experienced family conflict and violence, for example, a 16-year-old female user shared that her "brother and dad used to fight and then they physically fight with my mom." Smoking the hookah pipe with friends, however, provided positive emotions such as feeling happy, relaxed, and excited. A 17-year-old male user expressed, "When I get frustrated or aggressive, I will walk away and smoke. It makes me calmer. I'll go to my friend and we start talking and we will smoke the hookah pipe to relieve a little stress."

Users and nonusers also expressed negative feelings such as feeling lonely and unappreciated, but their experiences were different. Users experienced 
these feelings because they generally felt useless, helpless, unable to interact with a parent, isolated, or alone. A 16-year-old male user said, "I feel lonelythere is no one to talk to about my problems." Nonusers felt lonely when they were not acknowledged in team sports, or when they had to make emotional decisions. A 16-year-old female nonuser said, "Sometimes, I feel undervalued like they don't really see my value in team sport or schoolwork."

It can be concluded that users experienced needs frustration of relatedness to a greater extent compared to nonusers, leading to the need to smoke in a group in order to experience a sense of belonging.

\section{Motivation}

Intrinsic Motivation. Intrinsic motivation was described in terms of choice to smoke or not to smoke, enjoyment, and the belief that hookah smoking served as a coping mechanism or preventative measure. Hookah pipe users believed that smoking the hookah pipe helped them cope with life stressors because it was a means of relaxation. It also prevented them from joining a gang, smoking cigarettes, or smoking cannabis. This view was emphasized by a 17-yearold male user who said, "It helps me from joining a gang and looking for trouble. It helps me to be calm and to be on our own and relaxed." Hookah pipe users claimed to enjoy smoking the hookah pipe because of the amount of smoke, the ability to make shapes with the smoke, and the calming effect it had on them.

All hookah pipe users reported that they smoked out of their own free will and they did not feel forced to smoke. This is evidenced by a 16-year-old female users saying, "I do it out of my own free will because I want to, not because someone is forcing me or telling me."

Similarly, hookah pipe nonusers believed that they did not smoke because they chose not to smoke. Their reasons for not smoking included not liking the smell, having asthma, feeling that it was wrong to smoke the hookah pipe, and due to their participation in sport activities. A 16-year-old nonuser reported, "I don't smoke hookah. I don't like it. I tried it but it doesn't feel right."

Extrinsic Motivation. Extrinsic motivation included peer pressure, parental influence, environmental influence, money, and addiction. Even though hookah pipe users felt that they were smoking out of their own free will, some thought that peer pressure influenced their decision. Other users smoked to have friends, or because they did not know how to say no to their friends, while a few engaged in smoking to be popular. A 17-year-old male user indicated, "I only do it to keep my friends. All the friends I am with; they all do 
it. What is the use if I am with them, but I do not do it?" Despite peer pressure being rife, nonusers stood their ground and refused to give in. A 16-year-old female nonuser said, "I just tell them no, I don't smoke, they try to pressure me, but I don't give in easily."

Parents also played an important role in their decision to smoke or not smoke. When parents allowed hookah smoking, it encouraged users to smoke. Nonusers believed that smoking or not smoking was related to how well parents raised their children. They specifically made reference to rules at home and knowing that their parents - as significant role models - are nonsmokers. For example, an 18-year-old female user thought, "some people smoke just to show their friends, but I just do it because my mom allowed it" and a 16-year-old female nonuser felt, "I just don't feel the need to smoke because my parents don't smoke."

There was also the belief that the environment where one lives influences one's motivation to smoke as evidenced by 17 -year-old male user who claimed, "We grow up in a sick society and you get used to the idea, you have to be like this." Many of the adolescents reside in communities where smoking and substance abuse is rife. They spoke about how they witnessed substance abusers smoking the hookah pipe before they started using illegal substances. Hookah pipe users believed that by living in these communities, smoking was inevitable. Hookah pipe nonusers acknowledged the influence of the environment, yet they thought it was better not to conform to avoid falling into substance dependence. This was reflected by an 18-year-old male who shared, "I stopped smoking the hookah pipe because I come from an area where I see one thing [hookah] leads to another [cannabis]."

Users did not refer to money, but nonusers claimed that they were motivated not to use the hookah pipe because it was a waste of money. There was also a fear that they would need to steal if they were unable to satisfy their craving. A 16-year-old male nonuser shared, "I don't smoke because if I don't have money and if I craved for it, would I steal for it?"

Nonusers believed that smoking the hookah pipe was not addictive. A 16-year old female nonuser believed, "I think if I smoke, I won't get addicted to it." Some users agreed that that hookah pipe smoking was not addictive by stating, "Hookah users can change because it doesn't get addictive. You control it, it doesn't control you" (age 19 years, male), but others disagreed and felt that they were addicted, "it's almost as if I am addicted to it" (age 15 years, female).

Amotivation. Some hookah pipe users and nonusers are indifferent to smoking the hookah pipe. Hookah pipe users did not know why they smoked and believed that it did not help them in any way. This was evidenced by a 
15-year-old female user stating, "I do not know why I am smoking." Hookah pipe nonusers experimented but felt that it did not satisfy them, and they did not see anything good coming from it. An 18-year-old female nonuser reflected on her experience and stated, "I didn't see anything good come from smoking, so I did not see the use of smoking."

\section{Discussion}

This study aimed to (1) explore whether satisfaction or frustration of BPN contributes to hookah pipe use or nonuse, and (2) understand what motivates adolescents to smoke or not smoke the hookah pipe.

In some cases, there are distinct differences between users' and nonusers' BPN, and in other cases there are similarities between the two groups. For instance, both users and nonusers do not feel autonomous regarding decision making. SDT regards provision of choice as an important component of satisfaction of autonomy as it is associated with intrinsic motivation (MarbellPierre et al., 2019). The majority of adolescents were reliant on elders to guide them in decision making. Often a decision maker's main task is to discover the best way to attain a desirable outcome. Knowledgeable or experienced individuals are usually assumed to know the best way to proceed. Therefore, adolescents might seek advice from people whom they consider more knowledgeable (Byrnes, 2002).

However, some adolescents may still engage in risky behaviors, such as smoking the hookah pipe, despite receiving adequate knowledge (Byrnes, 2002). SDT asserts that the manner in which knowledge is shared with adolescents is very important. A controlling, directive, or authoritarian approach would be counterproductive, especially when trying to get adolescents to self-initiate a behaviour instead of simply complying (Moltafet et al., 2018). Essentially, adolescents experience a sense of freedom when they feel in control of a situation. Adolescents also experience a sense of freedom when they are able to experience and pursue a sense of personal curiosity (Ata et al., 2015). In this study, some adolescents appear to experience satisfaction of their need for autonomy, while others do not. The satisfaction or frustration is not necessarily specific to users or nonusers because both groups of adolescents' experience satisfaction and frustration of their need for autonomy. Therefore, it appears that participants' sense of autonomy does not necessarily contribute to whether they smoke the hookah pipe. The reason for this could be that the choice to smoke the hookah and having the need of autonomy fulfilled could be impacted by the ability to ask and receive support with decisions, protective or laissez-faire parenting, self-esteem, self-efficacy, peer group presence or absence, and role models, to name a few (Noller \& 
Callan, 2015). This would affect adolescents in general and is not specific to adolescent hookah pipe users or nonusers.

Competence, however, appears to have a contributory role as there appears to be distinct differences between the two groups. Many users indicate that they feel proud about smoking the hookah pipe and nonusers feel proud about not smoking. When adolescents feel proud, they feel more competent, and as a result, their intrinsic motivation to engage in an activity increases (Józsa et al., 2019). Users tend to give up quicker when they struggle, whereas nonusers tend to persevere more and try to accomplish the task. When adolescents feel competent, they perceive that they are capable of successfully performing and completing tasks (Deci \& Ryan, 2000). Furthermore, people perceive a greater sense of competence when they feel they are able to attain important health outcomes (Williams et al., 2006).

Adolescents also made reference to feeling useless and hopeless. Users' experiences tend to be more internalized as they feel that they cannot do anything right or that they are not good enough. Nonusers' sense of feeling useless and hopeless is related to external influences, such as their friends not listening to them. When adolescents internalize a sense of hopelessness, they may perceive negative thoughts, ideas, events, and experiences in their lives about their future and perceive little control over their life and overcoming obstacles (Eraslan-Capan, 2016). Naturally, this has a negative effect on their experiences of themselves, their sense of competence, and their well-being. This may lead them to engage in activities with their peers that makes them feel better, such as smoking the hookah pipe (Schacter \& Juvonen, 2019).

Both users and nonusers agree that smoking the hookah pipe allows one to fit into a social group. However, nonusers deliberately opt not to conform to the social norms of the group. This can be attributed to nonusers having better relationships with their family compared with users. Users describe an environment ridden with family conflict and violence. Typically, positive and nurturing experiences in the social environment of the adolescent allows for BPN to be met. This can be achieved by supportive parent and family relationships (Kader \& Roman, 2016; Schacter \& Juvonen, 2019). Similar to competence, users and nonusers feel lonely and unappreciated, but users' experiences are more internalized because they feel that they cannot interact with parents or speak to anyone compared with nonusers who feel lonely or unappreciated when they are not acknowledged in team sports. Adolescents' sense of relatedness is supported when the important people in their lives are involved, take a sincere interest in them, and are empathetic. When this does not occur, the need for relatedness is frustrated (Sebire et al., 2016). Based on the findings, it appears that adolescents' experience of satisfaction or 
frustration of relatedness may have a contributory role in adolescent hookah pipe use.

In terms of motivation, users and nonusers agree that smoking or not smoking the hookah is a process driven by intrinsic motivation, and they are smoking or not smoking as a result of their own free will. Users regard smoking as enjoyable and a coping mechanism to deal with life's stressors. However, both groups acknowledge external conditions, such as friends, parents, and environmental aspects, which contribute to the motivation for hookah pipe use or nonuse. This finding is corroborated by a study by Lakon et al. (2015) on the role of parents and friends in smoking behaviors. These authors found that adolescent friendship groups are a compelling socialization context in which friendship choice and smoking coevolve, and that parental monitoring was protective for smoking and appeared to decrease adolescent smoking. Gray et al. (2016) argue that people's ability to make choices about smoking is constrained by contextual and cognitive factors. They are therefore not intrinsically motivated to smoke but are in fact extrinsically motivated. However, there is limited insight into adolescents' intrinsic motivation to smoke because previous studies have mainly focused on motivation to stop smoking. This study found that adolescents experience intrinsic and extrinsic motivation to smoke the hookah pipe. In some cases, adolescents are amotivated. This is a relatively new perspective as previous studies found that adolescents mainly smoke as a result of extrinsic motivators (Bahelah et al., 2019; Cornacchione et al., 2016; Gray et al., 2016), but there is a belief that adolescents need to be intrinsically motivated to stop smoking (Curry et al., 1997; Thrul et al., 2015; Tombor et al., 2018).

It is important, therefore, to recognise the role of motivation and BPN in adolescents' motivation to smoke the hookah pipe. This can help practitioners to intervene by providing contexts to satisfy BPN and increase intrinsic motivation not to smoke the hookah pipe. The reduction of this practice will in turn help minimise the health consequences of hookah pipe smoking. This can lead to a healthier adolescent, healthier family, healthier community, and consequently, a healthier population. Improved health means less strain on health systems and the economy, improved productivity, and a better quality of life (Balabanova et al., 2013).

Important lessons can be derived from this research for teachers and parents or caregivers. As adolescents seek guidance from teacher and parents, it is important that adolescents are provided with information that would allow them to make informed decisions. Adolescents often have questions and concerns so it is vital that teachers and parents respond in a supportive manner rather than a punitive manner. This will allow adolescents to feel comfortable when seeking assistance and therefore make healthier decisions. Life skills 
sessions should be offered at school focusing on hookah pipe use, assertion training, positive friendships and informed decision making. This should be accompanied by homework where the adolescents can practice their skills at home with their parents and friends. This will equip adolescents with the necessary skills to reject hookah pipe smoking. Teachers and parents should create opportunities where adolescents can experience a sense of autonomy, competence, and relatedness by providing leadership opportunities, challenging but manageable tasks and establishing supportive spaces for adolescents to feel heard, encouraged, and accepted.

\section{Limitations and Future Research}

One possible limitation of this study was that the participants were exposed to the earlier quantitative study of this project to help them focus on the type of information of interest to the researcher. This exposure could have influenced how the adolescent answered questions during the in-depth interviews. However, since this was part of a project that made use of a sequential exploratory design, this was unavoidable. Future studies could make use of a sequential explanatory design where the quantitative study will build on the findings of the qualitative study. This could present different findings as the quantitative inquiry will be guided by the themes of the qualitative phase. Another area of future research could be to explore hookah pipe nonusers that experimented or stopped using in an attempt to understand why or how they stopped smoking.

\section{Conclusion}

This study sought to understand the contributory role of BPN and motivation in adolescent hookah pipe use. It was found that there is an overlap in need satisfaction and needs frustration amongst users and nonusers. This is especially true for the autonomy need, which may be influenced by other factors, such as self-esteem, parenting styles, and support systems. Satisfaction or frustration of the needs of competence and relatedness are more likely to influence hookah pipe use. Users appear to experience more needs frustration compared to hookah pipe nonusers. The choice to smoke or not to smoke is motivated by intrinsic and extrinsic motivation. In this regard, users are more extrinsically motivated to smoke, while nonusers are more intrinsically motivated not to smoke. This research offers a new perspective, as previous research has mostly focused on the extrinsic factors that motivate adolescents to smoke, often overlooking the human experience in substance use. 


\section{Declaration of Conflicting Interests}

The author(s) declared no potential conflicts of interest with respect to the research, authorship, and/or publication of this article.

\section{Funding}

The author(s) disclosed receipt of the following financial support for the research, authorship, and/or publication of this article: This work was supported by the Health and Welfare Sector Education and Training Authority Sciences under grant number (17/PGRB/L000335) and the National Institute for the Humanities and Social Sciences under grant number (SDS17/1878).

\section{ORCID iD}

Zainab Kader (iD https://orcid.org/0000-0001-9120-8242

\section{References}

Ata, D., Nguyen, H., Driver, P., \& Thorkildsen, T. A. (2015). Preserving autonomy and interest mediates adolescents' academic performance. Interdisciplinary Undergraduate Research Journal, 1(1), 14-21. https://www.scribd.com/ doc/310513502/ata-et-al-iurj2015

Bahelah, R., Ward, K. D., Taleb, Z. B., DiFranza, J. R., Eissenberg, T., Jaber, R., \& Maziak, W. (2019). Determinants of progression of nicotine dependence symptoms in adolescent waterpipe smokers. Tobacco Control, 28(3), 254-260. http:// doi.org/10.1136/tobaccocontrol-2018-054244

Balabanova, D., Mills, A., Conteh, L., Akkazieva, B., Banteyerga, H., Dash, U., Gilson, L., Harmer, A., Ibraimova, A., Islam, Z., Kidanu, A., Koehlmoos, T. P., Limwattananon, S., Muraleedharan, V. R., Murzalieva, G., Palafox, B., Panichkriangkrai, W., Patcharanarumol, W., Penn-Kekana, L., . . . McKee, M. (2013). Good Health at low cost 25 years on: Lessons for the future of health systems strengthening. Lancet, 381(9883), 2118-2133. https://doi.org/10.1016/ S0140-6736(12)62000-5

Bartholomew, B., Eldredge, L. K. B., Markham, C. M., Ruiter, R. A., Fernández, M. E., Kok, G., \& Parcel, G. S. (2016). Planning health promotion programs: an intervention mapping approach. John Wiley \& Sons.

Bashirian, S., Barati, M., Sharma, M., Abasi, H., \& Karami, M. (2019). Water pipe smoking reduction in the male adolescent students: An educational intervention using multi-theory model. Journal of Research in Health Science, 19(1), e00438. https://www.ncbi.nlm.nih.gov/pmc/articles/PMC6941630/

Braun, V., \& Clarke, V. (2006). Using thematic analysis in psychology. Qualitative Research in Psychology, 3(2), 77-101. https://doi.org/10.1191/1478088706qp0 $63 \mathrm{oa}$

Byrnes, J. P. (2002). The development of decision-making. Journal of Adolescent Health, 31(6), 208-215. https://doi.org/10.1016/S1054-139X(02)00503-7 
Combrink, A., Irwin, N., Laudin, G., Naidoo, K., Plagerson, S., \& Mathee, A. (2010). High prevalence of hookah smoking among secondary school students in a disadvantaged community in Johannesburg. South African Medical Journal, 100, 297-299. https://doi.org/10.7196/samj.3965

Cornacchione, J., Wagoner, K. G., Wiseman, K. D., Kelley, D., Noar, S. M., Smith, M. H., \& Sutfin, E. L. (2016). Adolescent and young adult perceptions of hookah and little cigars/cigarillos: Implications for risk messages. Journal of Health Communication, 21(7), 818-825. https://doi.org/10.1080/10810730.2016.1177141

Curry, S. J., Grothaus, L., \& McBride, C. (1997). Reasons for quitting: Intrinsic and extrinsic motivation for smoking cessation in a population-based sample of smokers. Addictive Behaviors, 22(6), 727-739. https://doi.org/10.1016/S03064603(97)00059-2

Daniels, K. E. (2012). Hookah pipe use: Comparing male and female university students' knowledge, risk perceptions and behaviours. Unpublished master's thesis. University of the Western Cape, South Africa.

Deci, E. L., \& Ryan, R. M. (2000). Self-determination theory and the facilitation of intrinsic motivation, social development, and well-being. American Psychologist, 55(1), 68-78. https://doi.org/10.1037/0003-066X.55.1.68

Eraslan-Capan, B. (2016). Social connectedness and flourishing: The mediating role of hopelessness. Universal Journal of Educational Research, 4(5), 933-940.

Eshah, N. F., \& Froelicher, E. S. (2017). Knowledge, attitudes, beliefs and patterns of waterpipe use among Jordanian adults who exclusively smoke waterpipes. European Journal of Cardiovascular Nursing, 17(1), 85-92. https://doi. org/10.1177/1474515117719592

Gray, R. J., Hoek, J., \& Edwards, R. (2016). A qualitative analysis of 'informed choice' among young adult smokers. Tobacco Control, 25(1), 46-51. http://doi. org/10.1136/tobaccocontrol-2014-051793

Jawad, M., \& Power, G. (2016). Prevalence, correlates and patterns of waterpipe smoking among secondary school students in southeast London: A cross-sectional study. BMC Public Health, 16, Article 108. https://doi.org/10.1186/ s12889-016-2770-1

Józsa, K., Kis, N., \& Barrett, K. C. (2019). Mastery motivation, parenting, and school achievement among Hungarian adolescents. European Journal of Psychology of Education, 34(2), 317-339. http://doi.org/10.1007/s10212-018-0395-8

Kader, Z., \& Roman, N. V. (2016). Self-determination theory and family conflict: A theoretical overview. In N. V. Roman \& E. L. Davids (Eds.), Self-determination theory: A family perspective (pp. 47-63). Nova Science.

Kader, Z., Roman, N. V., \& Crutzen, R. (2019). Systematic review of interventions aimed at reducing hookah pipe use: Implications for practitioners and clinicians. South African Medical Journal, 109(6), 392-406. https://doi.org/10.7196/ SAMJ.2019.v109i6.013892

Korstjens, I., \& Moser, A. (2018). Series: Practical guidance to qualitative research. Part 4: Trustworthiness and publishing, European Journal of General Practice, 24(1), 120-124. https://doi.org/10.1080/13814788.2017.1375092 
Kuzucu, Y., \& Şimşek, Ö. F. (2013). Self-determined choices and consequences: The relationship between BPN satisfactions and aggression in late adolescents. Journal of General Psychology, 140(2), 110-129. https://doi.org/10.1080/00221 309.2013.771607

Lakon, C. M., Wang, C., Butts, C. T., Jose, R., Timberlake, D. S., \& Hipp, J. R. (2015). A dynamic model of adolescent friendship networks, parental influences, and smoking. Journal of Youth and Adolescence, 44(9), 1767-1786. https://doi. org/10.1007/s10964-014-0187-7

Li, C., Ivarsson, A., Lam, L. T., \& Sun, J. (2019). BPN satisfaction and frustration, stress, and sports injury among university athletes: A four-wave prospective survey. Frontiers in Psychology, 10, Article 665. https://doi.org/10.3389/ fpsyg.2019.00665

Lincoln, Y. S., \& Guba, E. G. (1985). Naturalistic inquiry. Sage.

Marbell-Pierre, K. N., Grolnick, W. S., Stewart, A. L., \& Raftery-Helmer, J. N. (2019). Parental autonomy support in two cultures: The moderating effects of adolescents' self-construals. Child Development, 90(3), 825-845. https://doi. org/10.1111/cdev.12947|

Marshall, J. R., Lotfipour, S., \& Chakravarthy, B. (2016). Growing trend of alternative tobacco use among the nation's youth: A new generation of addicts. Western Journal of Emergency Medicine, 17(2), 139-142. https://doi.org/10.5811/ westjem.2016.1.29383

Maziak, W., Taleb, Z., \& Bahelah, R. (2015). The global epidemiology of waterpipe smoking. Tobacco Control, 24(Suppl. 1), 120-130. http://doi.org/10.1136/tobaccocontrol-2014-051903

Moltafet, G., Sadati Firoozabadi, S. S., \& Pour-Raisi, A. (2018). Parenting style, basic psychological needs, and emotional creativity: A path analysis. Creativity Research Journal, 30(2), 187-194. https://doi.org/10.1080/10400419.2018.1446 748

Moreno, M. (2015). Risks of hookah smoking. JAMA Pediatrics, 169(2), Article 196. https://doi.org/10.1001/jamapediatrics.2014.2110

Noller, P., \& Callan, V. (2015). The adolescent in the family. London

Peer, N. (2018). Current strategies are inadequate to curb the rise of tobacco use in Africa. South African Medical Journal, 108(7), 551-556. https://doi.org/10.7196/ SAMJ.2018.v108i7.12978

Petersen, T. (2018, June 24). Young kids take to hookah pipe smoking. Weekend Argus. https://www.iol.co.za/weekend-argus/young-kids-take-to-hookah-pipesmoking-15658181

Ramji, R., Nilsson, M., Arnetz, B., Wiklund, Y., \& Arnetz, J (2019). Taking a stand: An untapped strategy to reduce waterpipe smoking. Adolescents, Substance Use \& Misuse, 54(3), 514-524. https://doi.org/10.1080/10826084.2018.1521429

Ryan, R. M., Rigby, C. S., \& Przybylski, A. (2006). The motivational pull of video games: A self-determination theory approach. Motivation and Emotion, 30(4), 344-360. https://doi.org/10.1007/s11031-006-9051-8

Schacter, H. L., \& Juvonen, J. (2019). Dynamic changes in peer victimization and adjustment across middle school: Does friends' victimization alleviate distress? Child Development, 90(5), 1738-1753. https://doi.org/10.1111/cdev.13038| 
Sebire, S. J., Kesten, J. M., Edwards, M. J., May, T., Banfield, K., Tomkinson, K., Blair, P. S., Bird, E. L., Powell, J. E., \& Jago, R. (2016). Using self-determination theory to promote adolescent girls' physical activity: Exploring the theoretical fidelity of the Bristol Girls Dance Project. Psychology of Sport and Exercise, 24(May), 100-110. https://doi.org/10.1016/j.psychsport.2016.01.009

Sorsa, M. A., Kiikkala, I., \& Åstedt-Kurki, P. (2015). Bracketing as a skill in conducting unstructured qualitative interviews. Nurse Researcher, 22(4), 8-12. https:// doi.org/10.7748/nr.22.4.8.e1317

Thrul, J., Stemmler, M., Goecke, M., \& Bühler, A. (2015). Are you in or out? Recruitment of adolescent smokers into a behavioral smoking cessation intervention. Addictive Behaviors, 45(June), 150-155. https://doi.org/10.1016/j.addbeh.2015.01.030

Tombor, I., Vangeli, E., West, R., \& Shahab, L. (2018). Progression towards smoking cessation: Qualitative analysis of successful, unsuccessful, and never quitters. Journal of Substance Use, 23(2), 214-222. https://doi.org/10.1080/14659891.2 017.1378746

Tong, A., Sainsbury, P., \& Craig, J. (2007). Consolidated criteria for reporting qualitative research (COREQ): A 32-item checklist for interviews and focus groups. International Journal for Quality in Health Care, 19(6), 349-357. https://doi. org/10.1093/intqhe/mzm042

Williams, G. C., McGregor, H. A., Sharp, D., Levesque, C., Kouides, R. W., Ryan, R. M., \& Deci, E. L. (2006). Testing a self-determination theory intervention for motivating tobacco cessation: Supporting autonomy and competence in a clinical trial. Health Psychology, 25(1), 91-101. https://doi.org/10.1037/02786133.25.1.91

World Health Organization. (2015) Advisory note: Waterpipe tobacco smoking: Health effects, research needs and recommended actions for regulators. https:// www.who.int/tobacco/global_interaction/tobreg/Waterpipe\%20recommendation_Final.pdf

\section{Author Biographies}

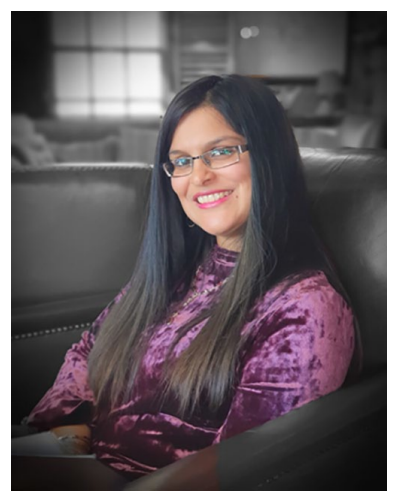

Dr. Zainab Kader is a registered counsellor with the Health Professions Council of South Africa and has a $\mathrm{PhD}$ in child and family studies. She has published research locally and internationally focusing on parenting interventions, family conflict and self determination theory, behavioural interventions, and systematic reviews related to hookah pipe smoking. Zainab has research and practical experience working with children, adolescents, and adults in resource-constrained environments who are exposed to an array of social ills. Her work focuses on designing and implementing interventions. Furthermore, she is a supervisor for students 
pursuing their postgraduate diploma in child and family studies and she is practicing as a registered counsellor focusing on trauma at the local municipality. She has been recognised by the Mail and Guardian as one of the top 200 young South Africans in 2020 .
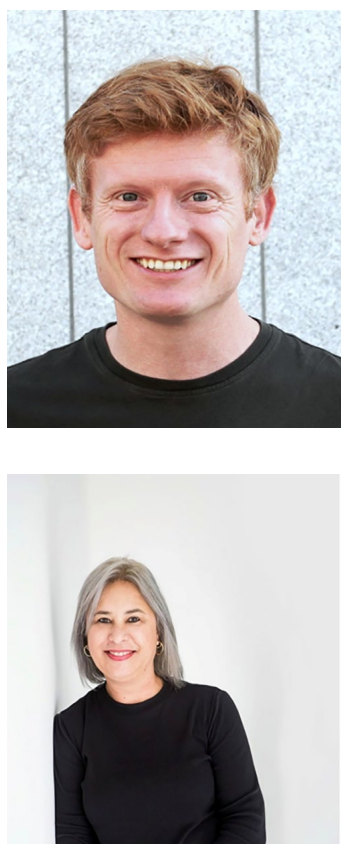

Professor Rik Crutzen is trained as a psychologist and holds a chair in behavior change and technology at Maastricht University, The Netherlands. He is experienced in developing, evaluating, and implementing behavior change interventions. The focus of his work is on how we can use technological innovations to improve both reach and efficacy of behavior change interventions.

Professor Nicolette Roman has a PhD in Psychology and is rated as an established researcher in South Africa. She currently holds the position of a South African Research Chair (SARChI) in the development of human capabilities and social cohesion through the Family in the Centre for Interdisciplinary Studies of Children, Families and Society, at the University of the Western Cape (UWC). She is also the PI growing the field of Early Childhood Development (ECD) at UWC. Her research focuses on family life, strengthening capable families through the family-parent-child relationship [including the role of fathers] across the lifespan ultimately achieving family and social cohesion. She has published and presented her research both locally and internationally, has grown the critical mass in family science in South Africa and has been awarded for research excellence in community and health science research. 